\title{
Prevalence of Methicillin-Resistant Staphylococcus aureus and Classical Enterotoxin Genes Among Sudanese Food Handlers
}

Omar B. Ahmed ${ }^{1}$

1. Department of Environmental and Health Research, Umm Al-Qura University, Makkah, SAU

Corresponding author: Omar B. Ahmed, abuaglah1@hotmail.com

\begin{abstract}
Food handlers who carry enterotoxin-producing Staphylococcus aureus could become potential reservoirs of Staphylococcal food poisoning. The study is a cross-sectional one aimed to determine the prevalence of methicillin-resistant $S$. aureus (MRSA) and staphylococcal enterotoxins from randomly selected food handlers in Al Jazirah state, Sudan. Culture swabs were collected from the hands and nasals of food handlers (2016-2018). Identification of $S$. aureus was done on the basis of conventional laboratory tests. All S. aureus isolates were screened for MRSA and staphylococcal enterotoxin (SE) genes by polymerase chain reaction. The $S$. aureus strains were isolated from $25 \%$ of the collected culture swabs of which $42 \%$ were confirmed as MRSA. The existence of one or more of enterotoxin genes was confirmed in $34.4 \%$ of the isolated $S$. aureus strains. The combined staphylococcal enterotoxin genes were found in $9.6 \%$ of the isolates. The SE genes among MRSA strains (61.5\%) were found to be higher than methicillin-sensitive S. aureus strains (14.8\%). The most frequent staphylococcal enterotoxin genes were SEA (19.4\%) followed by the SEB (8.6\%), SEC (4.3\%), and SED (2.1\%). The carriage rate of MRSA strains demonstrated a higher rate of staphylococcal enterotoxins genes than methicillin-sensitive $S$. aureus. There is an increasing prevalence of MRSA compared with the previous rates and staphylococcal enterotoxin genes among Sudanese food handlers, which is a serious problem for public health.
\end{abstract}

Categories: Medical Education, Infectious Disease, Public Health

Keywords: s. aureus, food handlers, enterotoxins, mrsa, mssa, sudan

\section{Introduction}

Foodborne diseases (FBDs), which involve a wide spectrum of illnesses caused by either microbial (bacteria, viruses, or parasitic) or chemical contamination of food, now have become a global health problem. It is estimated that more than 100 million people of the population in the Eastern Mediterranean region suffer from these diseases, whereas two million deaths in developing countries occurred annually [1,2]. In Sudan, a large number of consumers suffer from FBDs, some become ill, and some die from them. The increase in FBDs in Sudan requires a rapid and effective response. Staphylococcal food poisoning (SFP) is a common FBD which is known as an intoxication due to exposure to staphylococcal enterotoxins (SEs) [3]. SEs are considered exotoxins, insensitive to heat, irradiation produced by Staphylococcus aureus, and of low molecular weight [4]. The prevention of SFP has an important social and economic value in Sudan. The disease could influence people working days and productivity of the workers, in addition to the hospital expenses, and financial losses in food industries, catering companies, and restaurants [5]. The known types of SEs have reached 22 in number; half of this number has emetic action [5,6]. The classical SEs were designated with consecutive letters of the alphabet, from SEA to SEE, which are involved in 95\% of SFP outbreaks [7]. Food handlers may carry enterotoxin-producing $S$. aureus in their hands and secretions, hence they could become a potential source of SFP through direct contact or respiratory secretions. Methicillinresistant $S$. aureus (MRSA) have emerged from $S$. aureus through the staphylococcal cassette chromosome mec, (carrying the mecA gene) responsible for resistance to antibiotics such as methicillin and penicillin [8]. This study aimed to determine the prevalence of MRSA and SEs among $S$. aureus isolated from food handlers in Al Jazirah state, Sudan.

\section{Materials And Methods Collection of the samples}

This study was a descriptive qualitative cross-sectional laboratory-based study conducted in Al Jazirah state, Sudan, from July 2016 to July 2018. A total number of 372 swab specimens were collected from the nasal and hands (interdigital region, index fingers, thumbs, and palms of both right and left hands) of 186 food handlers who were working in different restaurants in different localities of Al Jazirah state. Valid consent was obtained from each subject under the study.

\section{Bacterial isolation and identification}


The swabs were immediately placed in a bacterial transport medium. They were directly inoculated onto blood agar, MacConkey agar (Oxoid, Cambridge, UK), and were incubated aerobically at $37^{\circ} \mathrm{C}$ for $18-24$ hours. Identification of $S$. aureus was done on the basis of conventional laboratory tests. After Gram stain, colonies of Gram positive cocci were tested with catalase, hemolysis on blood agar, coagulase, DNase tests in addition to culture properties on mannitol salt agar medium.

\section{MRSA and SEs screening}

For DNA extraction, bacteria were collected and pelleted after culturing in nutrient broth. The DNA was extracted by microwave lysis method, briefly, bacteria were collected, pelleted after culturing in nutrient broth, then washed and resuspended in $10 \%$ SDS. The suspensions were then incubated for 30 minutes at $65^{\circ} \mathrm{C}$. The pellets were centrifuged, the supernatants were removed, and the isolates were placed in a microwave oven and heated twice for one minute. The DNA was extracted by using the microwave method and phenol/chloroform/isoamyl alcohol method [9]. An aliquot of the DNA was electrophoresed on 1\% agarose gel to ensure the purity of extracted DNA. The samples were then screened for mecA [10] and the SE genes SEA, SEB, SEC, SED, and SEE by polymerase chain reaction (PCR), with specific primers (Table 1) $[10,11,12]$. The PCR reaction mixture $(25 \mu \mathrm{l})$ contained $5 \mu \mathrm{l}$ of DNA template, $1 \mu \mathrm{l}(100 \mathrm{pmol})$ of each primer, and $25 \mu$ l of Taq PCR Master Mix polymerase (Qiagen, Germantown, MD, USA). Amplification conditions were as follows: initial denaturation for five minutes at $94^{\circ} \mathrm{C}$, and then 30 cycles, each cycle consisting of denaturation at $94^{\circ} \mathrm{C}$ for two minutes and extension at $72^{\circ} \mathrm{C}$ for one minute. Annealing temperatures used for each step are shown in Table 1 . Final extension was performed at $72^{\circ} \mathrm{C}$ for five minutes. The PCR products were analyzed and visualized by electrophoresis in $1.5 \%$ agarose gel and stained with ethidium bromide $(2 \mu \mathrm{g})$ and were viewed under UVP BioDoct It Imaging System (Analytik Jena, Jena, Germany).

\begin{tabular}{|c|c|c|c|c|c|}
\hline SEs & Sequence & Size & Temp & Target & Reference \\
\hline mecA-P4 & TCCAGATTACAACTTCACCAGG & \multirow{2}{*}{162} & \multirow{2}{*}{53} & \multirow{2}{*}{ mecA } & \multirow{2}{*}{ [10] } \\
\hline mecA-P7 & СCACTTCATATCTTGTAACG & & & & \\
\hline SEA-1 & TTGGAAACGGTTAAAACGAA & \multirow{2}{*}{120} & \multirow{2}{*}{50} & \multirow{2}{*}{ SEA } & \multirow{2}{*}{ [11] } \\
\hline SEA-2 & GAACCTTCCCATCAAAAACA & & & & \\
\hline SEB-1 & TCGCATCAAACTGACAAACG & \multirow{2}{*}{478} & \multirow{2}{*}{50} & \multirow{2}{*}{ SEB } & \multirow{2}{*}{ [11] } \\
\hline SEB-2 & GCAGGTACTCTATAAGTGCC & & & & \\
\hline SEC-1 & GACATAAAAGCTAGGAATTT & \multirow{2}{*}{257} & \multirow{2}{*}{50} & \multirow{2}{*}{ SEC } & \multirow{2}{*}{ [11] } \\
\hline SEC-2 & AAATCGGATTAACATTATCC & & & & \\
\hline SED-1 & CTAGTTTGGTAATATCTCCT & \multirow{2}{*}{317} & \multirow{2}{*}{50} & \multirow{2}{*}{ SED } & \multirow{2}{*}{ [11] } \\
\hline SED-2 & TAATGCTATATCTTATAGGG & & & & \\
\hline SEE-1 & TAGATAAAGTTAAAACAAGC & \multirow{2}{*}{170} & \multirow{2}{*}{50} & \multirow{2}{*}{ SEE } & \multirow{2}{*}{ [12] } \\
\hline SEE-2 & TAACTTACCGTGGACCCTTC & & & & \\
\hline
\end{tabular}

\section{TABLE 1: Primers of the genes used in the study}

SEs = staphylococcal enterotoxins

\section{Statistical analysis}

Statistical analysis was done using Statistical Package for Social Sciences (SPSS) version 25 software (IBM Corp., Armonk, NY, USA). The chi-square test was used to compare frequency distribution of SE genes among MRSA and methicillin-sensitive $S$. aureus (MSSA) isolates ( $p<0.05$ was considered statistically significant).

\section{Results}

A total number of 372 swab specimens were collected from food handlers working in kitchens or cafeterias in Al Jazeera state, Sudan. The number of isolated S. aureus strains was 93 (25\%) as shown in Table 2. PCR results confirmed the existence of one or more of enterotoxin genes in 32 (34.4\%) out of total $S$. aureus strains (Table 2, Table 3). Overall, the total number of MRSA confirmed by PCR (Figure 1) was 39 (42\%). Of these MRSA strains, 24 (61.5\%) harbored at least one enterotoxin gene (Table 3). SEA was the highest detected gene (19.4\%) followed by SEB (8.6\%), SEC (4.3\%), SED (2.1\%), and SEE (0\%) (Table 2). The 


\section{Cureus}

combination $\mathrm{SE}(\mathrm{A}+\mathrm{C})$ genes were detected in $4.3 \%$ out of the total 93 of $S$. aureus strains followed by the SE $(\mathrm{A}+\mathrm{B})(3.2 \%)$, and $\mathrm{SE}(\mathrm{A}+\mathrm{D})(2.1 \%)$ as shown in Table 2 and Figures $2-3$. The co-existence of more than one enterotoxin gene was detected in nine (9.6\%) out of the total 93 of S. aureus strains as shown in Table 2 and Figures 3-4. Significantly, MRSA strains showed a higher prevalence (61.5\%) of SE genes than MSSA (14.8\%) $(\mathrm{P}<0.05)$.

\begin{tabular}{|c|c|c|c|}
\hline SE gene & No $(\%)$ & Combined SE genes & No (\%) \\
\hline SEA & 18 (19.4\%) & SE $(A+B)$ & 3 (3.2\%) \\
\hline SEB & 8 (8.6\%) & $\mathrm{SE}(\mathrm{A}+\mathrm{C})$ & $4(4.3 \%)$ \\
\hline SEC & $4(4.3 \%)$ & \multirow{3}{*}{ SE (A+D) } & \multirow{3}{*}{$2(2.1 \%)$} \\
\hline SED & $2(2.1 \%)$ & & \\
\hline SEE & $0(0 \%)$ & & \\
\hline Total & $32(34.4 \%)$ & Total & $9(9.6 \%)$ \\
\hline
\end{tabular}

TABLE 2: Frequency of the SE genes in the isolated S. aureus strains.

$\mathrm{SE}=$ staphylococcal enterotoxin

\begin{tabular}{|c|c|c|c|}
\hline SE genes & MRSA & MSSA & Total \\
\hline SEA & 14 (15.1\%) & $4(4.3 \%)$ & 18 (19.4\%) \\
\hline SEB & 6 (6.4\%) & 2 (2.1\%) & 8 (8.6\%) \\
\hline SEC & 2 (2.1\%) & 2 (2.1\%) & $4(4.3 \%)$ \\
\hline SED & 2 (2.1\%) & $0(0 \%)$ & 2 (2.1\%) \\
\hline SEE & $0(0 \%)$ & $0(0 \%)$ & $0(0 \%)$ \\
\hline Total & $24(61.5 \%)$ & $8(14.8 \%)$ & $32(34.4 \%)$ \\
\hline
\end{tabular}

TABLE 3: Distribution of the SE genes among the isolated MRSA and MSSA strains.

SE = staphylococcal enterotoxin, MRSA = Methicillin-resistant S. aureus, MSSA = methicillin-sensitive S. aureus

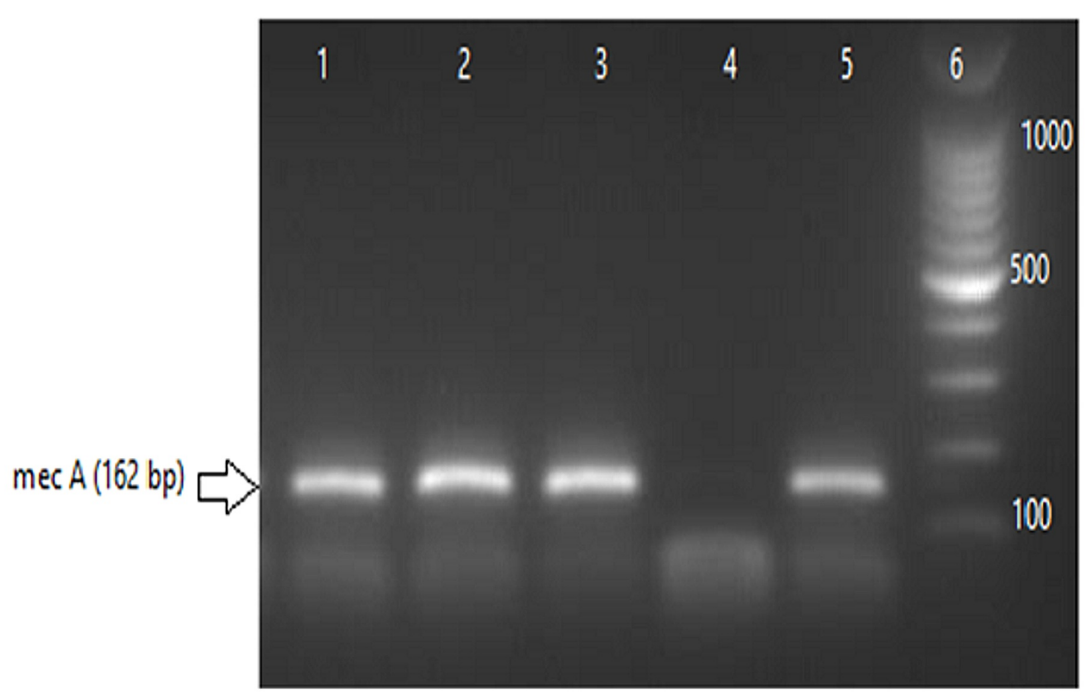

FIGURE 1: Detection of mecA gene on $2 \%$ agarose gel electrophoresis. 


\section{Cureus}

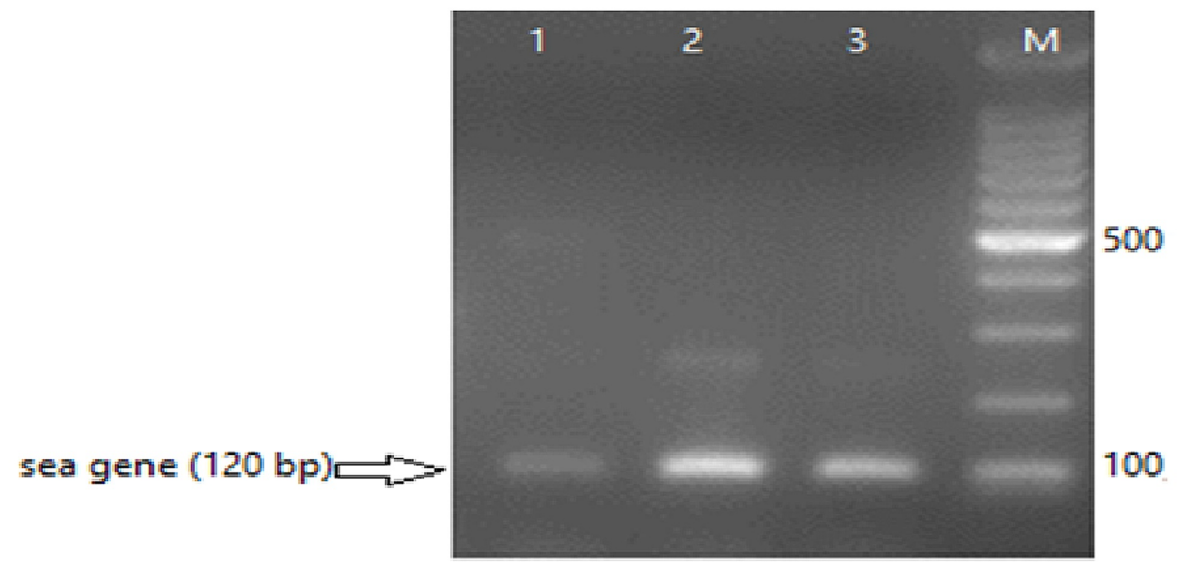

FIGURE 2: Detection of SEA gene on $2 \%$ agarose gel electrophoresis, lane M: 100-bp DNA ladder.

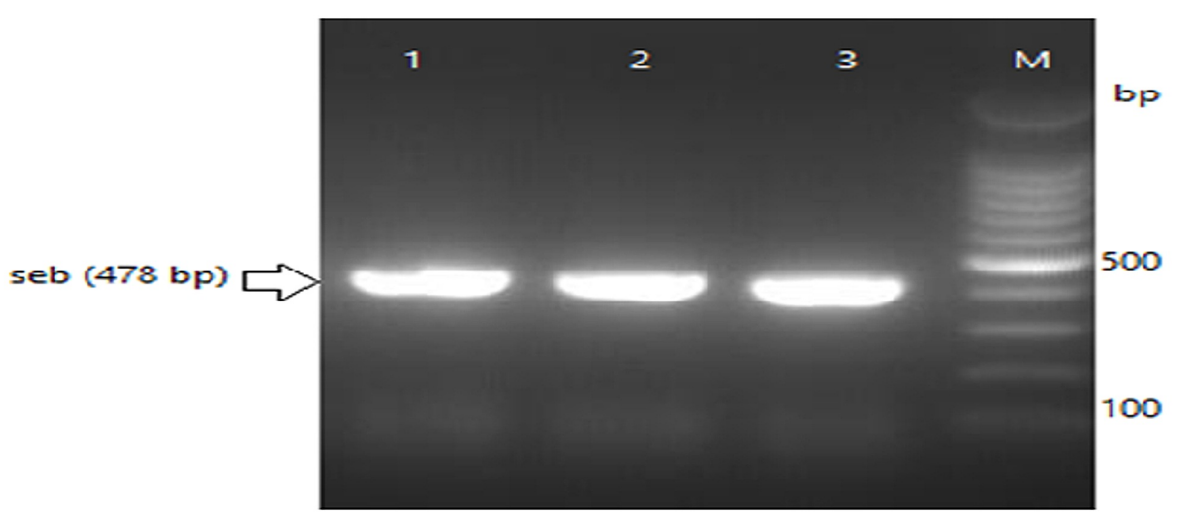

FIGURE 3: Detection of SEB genes on $2 \%$ agarose gel electrophoresis, lane M: 100-bp DNA ladder. 


\section{Cureus}

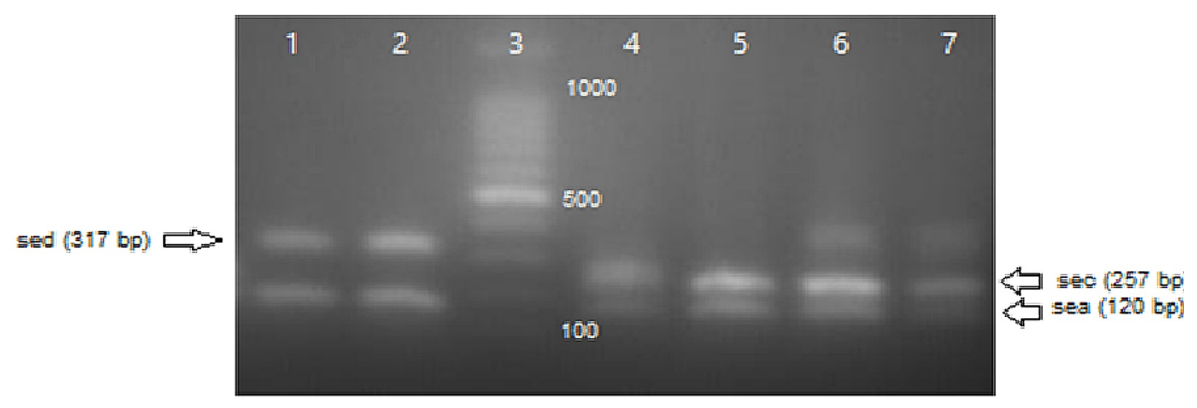

FIGURE 4: Coexistence enterotoxin genes on $2 \%$ agarose gel electrophoresis, lane M: 100-bp DNA ladder.

Discussion

Food handlers could be a potential source of foodborne illness or food poisoning which spread due to inadequate personal hygiene or from eating contaminated, spoiled, or toxic food. Bacteria is the most prevalent cause of food poisoning. The present study was undertaken to investigate the distribution of classical SE genes in S. aureus isolated from food handlers in Al Jazirah state, Sudan. The results showed that 93 (25\%) of the food handlers were carriers of S. aureus. The reported prevalence of S. aureus on the hands of food handlers is variable. Previous studies in Sudan reported that $21.6 \%$ of food handlers were found harboring S. aureus [13]. Studies from different countries have indicated that food handlers have a 20-30\% carriage rate of $S$. aureus [14-17], while others reported higher results (37.5\%) [18]. Also the study showed that $42 \%$ of $S$. aureus carried the mecA gene (MRSA). This finding is higher than Sezer et al., 2015 [19] (28.9\%), and lower than Loeto et al., 2007 (57.5\%) in Botswana [20]. The high prevalence of MRSA could be due to the extensive usage of antibiotics in the Al Jazirah community without prescription. The carriage of MRSA among food handlers could lead to development of multidrug-resistant bacteria and would become an important risk factor in the contamination of food as well as a source of staphylococcal human transmission $[21,22]$. The present study described classical SEs from SEA to SEE. PCR results confirmed the existence of enterotoxin genes in $34.4 \%$ of S. aureus isolates which is higher than Loeto et al., 2007 (21\%) [20], and lower than Figueroa et al. 2002 [23] (54\%) and Udo et al., 2009 [16] (71\%), respectively. The MRSA strains in the present study demonstrated a higher prevalence (61.5\%) of SE genes which is significantly higher than MSSA $(14.8 \%)(\mathrm{P}<0.05)$. This may be due to the possible handling of contaminated food and multiple infection with SFP among food handlers [24]. The present study showed that a combination of more than one enterotoxin gene was found in $9.6 \%$ of $S$. aureus isolates. The most frequent gene combination was SEA with SEC (4.3\%), similarly Fooladvand et al., 2019 [24] detected 40.8\%,14.7\%, and 1.9\% combination of two, three, or four SEs genes, respectively. Also, Udo et al., 2009 [16] demonstrated that 38\%, 20\%, and $7 \%$ of S. aureus isolates contained two, three, and four SE genes respectively. SEA was the most frequently detected gene (19.4\%) followed by SEB (8.6\%), SEC (4.3\%), SED (2.1\%), and SEE (0\%) genes. Worldwide, SEA has been described as the most common by many other authors $[18,25,26]$. This is in contrast to other studies conducted where the predominant SE gene was toxin SEB $[27,28]$. Worldwide, other enterotoxin genes have been described by many authors as in Poland SEC (17.5\%), SED (5\%), and SEE (0\%) [29], also in the Netherlands SEC (7.5\%), SED (1.9\%) and SEE (0\%) [26]. Food handlers carrying enterotoxin-producing $S$. aureus can contaminate food, and hence become a potential risk of food poisoning.

\section{Conclusions}

In conclusion, the prevalence of $S$. aureus in food handlers (25\%) is similar to the rate reported worldwide. The increasing prevalence of MRSA in food handlers in Sudan is a serious problem for public health. The high prevalence of SE genes indicates a potential risk of food poisoning. The MRSA strains in the present study demonstrated higher prevalence (61.5\%) of SE genes which is significantly higher than MSSA in Sudanese food handlers.

\section{Additional Information}

\section{Disclosures}


Human subjects: Consent was obtained by all participants in this study. Animal subjects: All authors have confirmed that this study did not involve animal subjects or tissue. Conflicts of interest: In compliance with the ICMJE uniform disclosure form, all authors declare the following: Payment/services info: All authors have declared that no financial support was received from any organization for the submitted work. Financial relationships: All authors have declared that they have no financial relationships at present or within the previous three years with any organizations that might have an interest in the submitted work. Other relationships: All authors have declared that there are no other relationships or activities that could appear to have influenced the submitted work.

\section{References}

1. Dagnew M, Tiruneh M, Moges F, Tekeste Z: Survey of nasal carriage of Staphylococcus aureus and intestinal parasites among food handlers working at Gondar University, Northwest Ethiopia. BMC Public Health. 2012, 12:837. 10.1186/1471-2458-12-837

2. WHO's First Ever Global Estimates of Foodborne Diseases Find Children Under 5 Account for Almost One Third of Deaths. (2015). Accessed: 11 October: https://www.who.int/news/item/03-12-2015-who-s-firstever-global-estimates-of-foodborne-diseases-find-children-under-....

3. Castro A, Santos C, Meireles H, Silva J, Teixeira P: Food handlers as potential sources of dissemination of virulent strains of Staphylococcus aureus in the community. J Infect Public Health. 2016, 9:153-60. 10.1016/j.jiph.2015.08.001

4. Pinchuk IV, Beswick EJ, Reyes VE: Staphylococcal enterotoxins. Toxins. 2010, 2:2177-2197. 10.3390/toxins2082177

5. Argudín MÁ, Mendoza MC, Rodicio MR: Food poisoning and Staphylococcus aureus enterotoxins . Toxins (Basel). 2010, 2:1751-73. 10.3390/toxins2071751

6. Hennekinne J-A, Ostyn A, Guillier F, Herbin S, Prufer A-L,Dragacci S: How should staphylococcal food poisoning out-breaks be characterized?. Toxins. 2010, 2:2106-16. 10.3390/toxins2082106

7. Jay MJ, Loessner JM, Golden AD: Staphylococcal gastroenteritis. Modern Food Microbiology. Springer Science, New York; 2005. 545:560.

8. Grema HA, Geidam YA, Gadzama GB, Ameh JA, Suleiman A: Methicillin resistant Staphyloccus aureus (MRSA): a review. Adv Anim Vet Sci. 2015, 3:79-98. 10.14737/journal.aavs/2015/3.2.79.98

9. Ahmed OB, Asghar AH, Elhassan MM: Comparison of three DNA extraction methods for polymerase chain reaction (PCR) analysis of bacterial genomic DNA. Afr J Microbiol Res. 2014, 8:598-602. 10.5897/ajmr2013.6459

10. Milheiriç OC, Oliveira DC, de Lencastre H: Update to the multiplex PCR strategy for assignment of mec element types in Staphylococcus aureus. Antimicrob Agents Chemother. 2007, 51:3374-3377. 10.1128/AAC.00275-07

11. Johnson WM, Tyler SD, Ewan P, Ashton FE, Pollard DR, Rozee KR: Detection of genes for enterotoxins, exfoliative toxins, and toxic shock syndrome toxin 1 in Staphylococcus aureus by the polymerase chain reaction. J Clin Immunol. 1991, 29:426-430.

12. Taj Y, Fatima I, Ali SW, Kazmi SU: Detection of genes for superantigen toxins in methicillin-resistant Staphylococcus aureus clinical isolates in Karachi. J Coll Physicians Surg Pak. 2014, 24:101-5.

13. Saeed HA, Hamid HH: Bacteriological and parasitological assessment of food handlers in the Omdurman area of Sudan. J Microbiol Immunol Infect. 2010, 43:70-3. 10.1016/S1684-1182(10)60010-2

14. Belkum VA, Verkaik NJ, Vogel CP, et al.: Reclassification of Staphylococcus aureus nasal carriage types . J Infect Dis. 2009, 199:1820-1826. 10.1086/599119

15. Hatakka M, Björkroth KJ, Asplund K, Mäki-Petäys N,Korkeala HJ: Genotypes and enterotoxicity of Staphylococcus aureus isolated from the hands and nasalcavities of flight-catering employees. J Food Prot. 2000, 63:1487-91. 10.4315/0362-028x-63.11.1487

16. Udo EE, Al-Mufti S, Albert MJ: The prevalence of antimicrobial resistance and carriage of virulence genes in Staphylococcus aureus isolated from food handlers in Kuwait city restaurants. BMC Res Notes. 2009, 2:10810. 10.1186/1756-0500-2-108.

17. Gashaw A, Kassu A, Moges F, Tiruneh M, Huruy K: Prevalence of bacteria and intestinal parasites among food-handlers in Gondar Town, Northwest Ethiopia. J Health Popul Nutr. 2008, 26:451-455. 10.3329/jhpn.v26i4.1887

18. Jordá GB, Marucci RS, Guida AM, Pires PS, Manfredi EA: Portación y caracterización de Staphylococcus aureus en manipuladores de alimentos [Carriage and characterization of Staphylococcus aureus in food handlers]. Rev Argent Microbiol. 2012, 44:101-4.

19. Sezer C, Celebi O, Aksoy A, Vatansever L: Food Handlers: a bridge in the journey of enterotoxigenic MRSA . Food. 2015, 10:123-129. 10.1007/s00003-015-0939-7

20. Loeto D, Matsheka MI, Gashe BA: Enterooxigenic and antibiotic resistance determination of Staphylococcus aureus strains isolated from food handlers in Gaborone, Botswana. J Food Prot. 2007, 70:2764-2768. 10.4315/0362-028x-70.12.2764

21. Balaban N, Rasooly A: Staphylococcal enterotoxins. Int J Food Microbiol. 2000, 61:1-10. 10.1016/s01681605(00)00377-9

22. Le Loir Y, Baron F, Gautier M: Staphylococcus aureus and food poisoning. Genet Mol Res. 2003, 31:63-76.

23. Figueroa G, Navarrete P, Caro M, Troncoso M, Faúndez G: [Carriage of enterotoxigenic Staphylococcus aureus in food handlers]. Revista Medica de Chile. 2002, 130:859-864.

24. Fooladvand S, Sarmadian H, Habibi D, et al.: High prevalence of methicillin resistant and enterotoxin genepositive Staphylococcus aureus among nasally colonized food handlers in central Iran. Eur J Clin Microbiol Infect Dis. 2019, 38:87-92. 10.1007/s10096-018-3398-0

25. Peck KR, Baek JY, Song H, Ko KS: Comparison of genotypes and enterotoxin genes between Staphylococcus aureus isolates from blood and nasal colonizers in a Korean hospital. J Korean Med Sci. 2009, 24:585-591. 10.3346/jkms.2009.24.4.585 


\section{Cureus}

26. Mehrotra M, Wang G, Johnson WM: Multiplex PCR for detection of genes for Staphylococcus aureus enterotoxins, exfoliative toxins, toxic shock syndrome toxin 1, and methicillin resistance. J Clin Microbiol. 2000, 38:1032-1035. 10.1128/JCM.38.3.1032-1035.2000

27. Al Bustan MA, Udo EE, Chugh TD: Nasal carriage of enterotoxin- producing Staphylococcus aureus among restaurant workers in Kuwait City. Epidemiol Infect. 1996, 116:319-22. 10.1017/s0950268800052638

28. Alhashimi HM, Ahmed MM, Mustafa JM: Nasal carriage of enterotoxigenic Staphylococcus aureus among food handlers in Kerbala city. Karbala Int J Mod Sci. 2017, 3:69-74. 10.1016/j.kijoms.2017.02.003

29. Bania J, Dabrowska A, Korzekwa K, Zarczynska A, Bystron J, Chrzanowska J, Molenda J: The profiles of enterotoxin genes in Staphylococcus aureus from nasal carriers. Lett Appl Microbiol. 2006, 42:315-320. 